\title{
Abordagem diagnóstica e terapêutica das mastocitoses - Uma proposta de orientação clínica
}

\section{Diagnostic and treatment approaches to mastocytosis - A proposal for clinical guidelines}

\footnotetext{
Rev Port Imunoalergologia $2020 ; 28$ (I): 3 I-49
}

\author{
Tiago Azenha Rama',2, André Moreira ${ }^{1,2,3,4}$, Luís Delgado',2,5 \\ I Serviço de Imunoalergologia, Centro Hospitalar Universitário São João, Porto \\ 2 Serviço de Imunologia Básica e Clínica, Departamento de Patologia, Faculdade de Medicina, Universidade do Porto \\ ${ }^{3}$ Faculdade de Ciências da Nutrição e Alimentação da Universidade do Porto \\ ${ }^{4}$ Instituto de Saúde Pública da Universidade do Porto \\ ${ }^{5}$ CINTESIS - Centro de Investigação em Tecnologias e Serviços de Saúde, Faculdade de Medicina, Universidade do Porto
}

\section{RESUMO}

As mastocitoses são um grupo de doenças raras e clonais dos mastócitos. No passado, a sua abordagem passou pela eviç̧ão de todos os fármacos, meios de contraste, alimentos e procedimentos descritos como ativadores dos mastócitos. Atualmente, existem diversos documentos orientadores a nível internacional que contrariam esta abordagem, sendo que em Portugal não existem ainda normas de orientação clínica. Esta proposta pretende fornecer linhas orientadoras para a abordagem clínica das mastocitoses.

O diagnóstico deve ser baseado na biópsia cutânea (quando existe envolvimento cutâneo) e no estudo da medula óssea. Todos os doentes devem ser portadores de documentação sobre fatores descadeadores a evitar. $O$ tratamento deve ser individualizado, podendo incluir cromoglicato de sódio, anti-histamínicos HI e/ou H2, entre outros. Devem ser fornecidos aos doentes esquemas de pré-medicação a realizar antes de procedimentos cirúrgicos, parto e utilização de meios de contraste iodados.

Palavras-chave: Mastocitose, mastócitos, mastocitose sistémica, mastocitose cutânea. 


\section{ABSTRACT}

Mastocytosis are a heterogeneous group of rare clonal mast cell diseases. In the past, mastocytosis management included a strict avoidance of all drugs, contrast media, foods and procedures ever described as mast cell activators. In the present, several international guidelines have emerged, proposing a more tailored approach, however in Portugal there are no current clinical guidelines. This proposal for management of mastocytosis intends to offer guidelines to the Portuguese clinician.

Diagnosis should be based on a skin biopsy (when there are skin lesions) and on bone marrow examination. All patients should have documentation on their disease and triggers that should be avoided. Treatment should be personalized and may include cromolyn sodium, $\mathrm{HI}$ andlor $\mathrm{H} 2$ antihistamines, among others. Patients should be given premedication protocols to be implemented before surgical procedures, labour and use of iodinated contrast media.

Keywords: Mastocytosis, mast cells, cutaneous mastocytosis, systemic mastocytosis.

\section{Lista de acrónimos e abreviaturas}

AAAAI - Academia Americana de Alergia, Asma e Imunologia AINEs - Anti-inflamatórios não esteroides

$C D$ - cluster of differentiation

COX - cicloxigenase

$\mathrm{EAACl}$ - Academia Europeia de Alergologia e Imunologia Clínica

ECNM - Rede Europeia de Competência em Mastocitose EV - endovenoso HUMARA - human androgen receptor assay IgE - imunoglobulina $\mathrm{E}$

IM - intramuscular

LM - leucemia mastocitária

MCMP - mastocitoses cutâneas maculopapulares

MS - mastocitose sistémica
MSA - mastocitose sistémica agressiva

MSA-t - mastocitose sistémica agressiva em transformação leucémica

MSBD - mastocitose sistémica bem diferenciada

$\mathrm{MSI}$ - mastocitose sistémica indolente

MSNHA - mastocitose sistémica com neoplasia hematológica associada

OMS - Organização Mundial de Saúde

PO - per os

PUVA - psoraleno com UVA

REMA - Red Española de Mastocitosis

SCF - stem cell factor

XCIP - inativação do cromossoma $X$

\section{INTRODUÇÃO}

A s mastocitoses são um grupo heterogéneo de doenças clonais dos mastócitos, que podem estar sobreativados e/ou acumular-se nos mais diversos órgãos e sistemas'. Estima-se que a prevalência desta doença ronde os 10 casos por cada 100000 habitantes ${ }^{2,3}$. Trata-se de um grupo de patologias que apresenta um curso clínico muito diverso e que, por vezes, se tornam difíceis de abordar clinicamente. A etiologia destas patologias decorre, em cerca de $95 \%$ dos casos, de mutações no gene KIT - proto-oncogene que codifi- ca um recetor transmembranar com função de cinase de tirosina, c-kit, cujo ligando, stem cell factor (SCF), promove a diferenciação, maturação, proliferação, adesão, quimiotaxia, sobrevivência e ativação dos mastócitos ${ }^{4-6}$.

Existem três grandes formas de apresentação: lesões cutâneas, anafilaxia e sintomas constitucionais decorrentes de doença hematológica. $\mathrm{O}$ stress emocional constitui-se como um dos grandes fatores de agudização ${ }^{7,8}$. Assim, estes doentes carecem de um acompanhamento multidisciplinar que muitas vezes deve incluir, no mínimo, Imunoalergologia, Hematologia, Dermatologia e Psicologia/Psiquiatria. 
Dada a sua reduzida prevalência, a abordagem dos doentes com mastocitose foi baseada, no passado, em evidência decorrente de casos clínicos, que refletiam a hipersensibilidade e a hiperreatividade destes doentes face a determinados fatores. Esta forma de abordagem pressupunha a eviç̧ão estrita de todos os fármacos, meios de contraste, alimentos e procedimentos alguma vez descritos (por vezes, uma única vez) como desencadeadores de reações decorrentes da libertação de mediadores mastocitários. À medida que se foram formando grupos de investigação e instituições de referência, têm surgido documentos orientadores e/ou de consenso sobre a abordagem clínica das mastocitoses, em diversos países ${ }^{9-12}$. Existem, também, documentos de consenso sobre hipersensibilidade a fármacos nas mastocitoses ${ }^{13}$ e sobre a abordagem de formas cutâneas pediátricas ${ }^{14}$. Porém, em Portugal, não existem, por ora, documentos de orientação clínica para a abordagem das mastocitoses.

Esta proposta de orientação clínica reúne alguma da evidência mais recente sobre este grupo de patologias e pretende fornecer linhas orientadoras sobre a abordagem clínica das mastocitoses.

\section{MATERIAL E MÉTODOS}

Esta proposta de orientação clínica das mastocitoses resulta de uma pesquisa efetuada em bases de dados indexadas (Medline ${ }^{\circledR}$, Scopus ${ }^{\circledR}$ ), utilizando como motores de busca o Pubmed.com e o Google Scholar ${ }^{\circledR}$. Foram

Quadro I. Classificação dos níveis de evidência e força de recomendação

\begin{tabular}{|c|c|c|c|}
\hline $\begin{array}{l}\text { Nível de } \\
\text { evidência }\end{array}$ & Definição & Implicações & Fonte de informação \\
\hline Alto & $\begin{array}{l}\text { O nível de confiança de que o } \\
\text { verdadeiro efeito seja próximo } \\
\text { do estimado é elevado. }\end{array}$ & $\begin{array}{l}\text { É improvável que estudos } \\
\text { futuros venham a alterar o } \\
\text { grau de confiança no poder } \\
\text { estimativo do efeito. }\end{array}$ & $\begin{array}{l}\text { - Ensaios clínicos bem desenhados com } \\
\text { amostra representativa; } \\
\text { - Estudos observacionais desenhados com } \\
\text { achados consistentes. }\end{array}$ \\
\hline Moderado & $\begin{array}{l}\text { O nível de confiança de que o } \\
\text { verdadeiro efeito seja próximo } \\
\text { do estimado é moderado. }\end{array}$ & $\begin{array}{l}\text { É possível que estudos futuros } \\
\text { venham a alterar o grau de } \\
\text { confiança no poder estimativo } \\
\text { do efeito e, inclusivamente, a } \\
\text { própria estimativa. }\end{array}$ & $\begin{array}{l}\text { - Ensaios clínicos com limitações leves } \\
\text { - Estudos observacionais bem delineados, } \\
\text { com achados consistentes. }\end{array}$ \\
\hline Baixo & $\begin{array}{l}\text { O nível de confiança de que o } \\
\text { verdadeiro efeito seja próximo } \\
\text { do estimado é limitado. }\end{array}$ & $\begin{array}{l}\text { É provável que estudos futuros } \\
\text { venham a alterar o grau de } \\
\text { confiança no poder estimativo } \\
\text { do efeito. }\end{array}$ & $\begin{array}{l}\text { - Ensaios clínicos com limitações } \\
\text { moderadas; } \\
\text { - Estudos observacionais comparativos: } \\
\text { coorte e caso-controlo. }\end{array}$ \\
\hline Muito baixo & $\begin{array}{l}\text { O nível de confiança de que o } \\
\text { verdadeiro efeito seja próximo } \\
\text { do estimado é muito limitado. }\end{array}$ & $\begin{array}{l}\text { Qualquer estimativa de efeito } \\
\text { é incerta. }\end{array}$ & $\begin{array}{l}\text { - Ensaios clínicos com limitações graves; } \\
\text { - Estudos observacionais comparativos, } \\
\text { com limitações; } \\
\text { - Estudos observacionais não } \\
\text { comparativos; } \\
\text { - Opinião de especialistas. }\end{array}$ \\
\hline \multicolumn{4}{|c|}{ Força de recomendação } \\
\hline Forte & \multicolumn{3}{|c|}{ Os benefícios da intervenção ultrapassam, claramente, o risco. } \\
\hline Moderada & \multicolumn{3}{|c|}{ Os benefícios da intervenção podem ultrapassar o risco. } \\
\hline Fraca & \multicolumn{3}{|c|}{ A relação risco/benefício é equilibrada, ou existe um grau considerável de incerteza face à magnitude do risco. } \\
\hline
\end{tabular}


utilizados artigos subordinados a questões relacionadas com as mastocitoses, publicados nos últimos 10 anos, com particular enfoque em artigos publicados por autores provenientes de centros de referência e em publicações de consenso. Pontualmente, foram utilizados artigos publicados há mais de 10 anos que mantêm relevância no momento atual. A redação desta proposta foi elaborada sob a forma habitualmente utilizada nas Normas de Orientação Clínica da Direção-Geral de Saúde, por forma a tornar a sua leitura/consulta mais familiar para clínicos de diferentes áreas de diferenciação ${ }^{15}$.

$\mathrm{Na}$ secção relativa à abordagem terapêutica, as classificações de qualidade de evidência e de força de recomendação utilizadas estão elencadas no Quadro I.

\section{PROPOSTA DE ORIENTAÇÃO CLÍNICA DAS MASTOCITOSES}

I. As mastocitoses são um grupo heterogéneo de doenças clonais dos mastócitos, provocadas, em cerca de $95 \%$ dos casos, pela mutação ativante do KIT, D816 ${ }^{16}$.

2. Espetro clínico: a apresentação clínica destas doenças é muito variável ${ }^{17}$, podendo estar envolvidos os seguintes órgãos/sistemas orgânicos:

2.I. Pele - órgão mais frequentemente envolvido, nomeadamente, em $\operatorname{crianças}^{18}$. As lesões podem apresentar um aspeto maculopapular, nodular, ou em placas, sendo englobadas nas mastocitoses cutâneas maculopapulares $(\mathrm{MCMP})^{18}$. Podem surgir mastocitomas, mais frequentemente únicos (mastocitoma cutâneo) ${ }^{19}$. Menos frequentemente, ocorre envolvimento cutâneo difuso com eritrodermia (mastocitose cutânea difusa), associada a episódios frequentes de libertação maciça de mediadores mastocitários ${ }^{18}$.

2.I.I. Ao contrário do que acontece nas crianças, em que o envolvimento cutâneo não é um fator preditivo para a presença de envolvimento sistémico, no adulto a presença de mastocitose na pele está quase invariavelmente associada a envolvimento sistémico ${ }^{20}$.
2.I.2. No que diz respeito à MCMP, consideram-se duas grandes variantes:

2.I.2.I. MCMP pediátrica: surge mais frequentemente na primeira infância. As lesões são, geralmente, polimórficas, portanto heterogéneas/assimétricas no que diz respeito ao seu tamanho e distribuição corporal e podem apresentar tamanho superior a $1 \mathrm{~cm}$. A cor das lesões é variável, podendo apresentar uma coloração avermelhada, acastanhada ou amarelada. Envolvem, frequentemente, a cabeça, nomeadamente a face e as extremidades, contrastando com o que se verifica na MCMP do adulto. Apesar da sua denominação (MCMP), esta variante inclui as formas nodulares e em placas. Ainda que não seja frequente, podem surgir lesões monomórficas, típicas da MCMP do adulto, em crianças. Esta variante está frequentemente associada a persistência na idade adulta e envolvimento sistémico ${ }^{18}$.

2.I.2.2. MCMP do adulto: as lesões apresentam tamanho reduzido e são homogéneas (monomórficas) no que diz respeito ao tamanho e, por vezes, distribuição corporal. Apresentam uma coloração avermelhada intensa/acastanhada, que no passado the conferiram a denominação de urticaria pigmentosa, atualmente em desuso. Poupa habitualmente a cabeça, envolvendo habitualmente $o$ tronco e as coxas. Está quase invariavelmente associada a envolvimento sistémico ${ }^{18}$.

2.I.3. O envolvimento cutâneo é muito frequente em doentes com mastocitoses sistémicas ${ }^{21}$. Surge em cerca de $50 \%$ das mastocitoses sistémicas agressivas e em menos de $50 \%$ das leucemias de mastócitos ${ }^{18,22}$.

2.I.4. Tipicamente, a fricção leve das lesões, utilizando por exemplo uma espátula de madeira, resulta no aparecimento de eritema, por vezes associado a edema das lesões - sinal de Darier. Quando pesquisado em lesões, ou áreas lesionais de grandes dimensões e em doentes particularmente suscetíveis, a pesquisa do sinal de Darier pode desencadear anafilaxia ${ }^{18}$.

2.I.5. Para além do envolvimento cutâneo macroscopicamente evidente, surgem outros sintomas cutâneos/ /mucocutâneos com bastante frequência: 
2.I.5.I. Prurido - muito frequente, pode ser incapacitante em alguns doentes. Pode estar presente em doentes com mastocitoses sistémicas sem envolvimento cutâneo ${ }^{23}$;

\section{I.5.2. Flushing}

\subsubsection{Angioedema}

2.2. Trato gastrointestinal - a sintomatologia gastrointestinal é muito prevalente, sendo que os doentes referem frequentemente epigastralgia, pirose, cólicas, diarreia/aumento do número de dejeções, com fezes de caráter mole ${ }^{17}$. Pode ocorrer envolvimento da cavidade oral ${ }^{24,25}$.

2.3. Medula óssea e sistema hematopoiético - as mastocitoses sistémicas apresentam invariavelmente envolvimento medular. Em formas avançadas podem ocorrer citopenias graves, esplenomegalia e hepatomegalia, e sintomas constitucionais ${ }^{17}$. Os doentes com mastocitose apresentam um risco aumentado para o aparecimento de neoplasias hematopoiéticas ${ }^{26}$.

2.4. Osso - frequentemente, surge diminuição da densidade mineral óssea, sob a forma de osteopenia e/ ou osteoporose $e^{26,27}$. A presença de osteoporose idiopática deve aliás levantar a suspeita de mastocitose ${ }^{27,28}$. Nas formas avançadas/agressivas, em particular, a osteoporose pode coexistir com um aumento focal (em placas)/ /difuso da densidade mineral óssea, sob a forma de osteosclerose $\mathrm{e}^{29,30}$.

2.5. Sistema cardiovascular - hipotensão, síncope, taquiarritmias. Não é infrequente a presença de sintomatologia prodrómica antes da perda de consciência associada a vasodilatação sistémica maciça ${ }^{3 !}$. Paradoxalmente, podem surgir quadros de vasospasmo associados à libertação de mediadores que podem resultar em síndromes coronárias agudas, quer na ausência de fatores de risco para doença arterial coronária (síndrome de Kounis tipo I), quer na presença de evidência angiográfica de doença arterial coronária (síndrome de Kounis tipo II) ${ }^{32}$.

2.6. Sistema nervoso central - diminuição da capacidade de concentração e atenção, baixa motivação, ansiedade, flutuação do humor, irritabilidade, depressão $33-35$ e cefaleias (nomeadamente enxaqueca) ${ }^{36}$.
2.7. Anafilaxia - a prevalência de anafilaxia nas mastocitoses é mais alta do que na população em geral ${ }^{37,38}$, ainda que a prevalência de atopia seja semelhante à verificada na população geral ${ }^{39}$. É particularmente frequente nos doentes com mastocitoses sistémicas sem envolvimento cutâneo ${ }^{37,38}$.

3. Classificação: a classificação das mastocitoses tem sido proposta pela OMS (2016), descrevendo-se no Quadro $2^{16}$.

Quadro 2. Classificação das mastocitoses, segundo a OMS $(2016)^{15}$

\begin{tabular}{|l|}
\hline \multicolumn{2}{|c|}{ Mastocitose cutânea } \\
\hline Mastocitose cutânea maculopapular \\
\hline Mastocitose cutânea difusa \\
\hline Mastocitoma da pele \\
\hline \multicolumn{2}{|c|}{ Mastocitose sistémica* } \\
\hline Mastocitose sistémica indolente \\
\hline Mastocitose sistémica quiescente (smoldering) \\
\hline Mastocitose sistémica com neoplasia hematológica \\
associada
\end{tabular}

*Todas as mastocitoses sitémicas podem ter ou não envolvimento cutâneo e podem ou não ser bem diferenciadas (BD).

\section{Diagnóstico:}

4.I. Existem três grandes formas de apresentação das mastocitoses: lesões cutâneas, episódios de anafilaxia e sintomas constitucionais, ambos na presença ou ausência de lesões cutâneas. 
4.I.I. Suspeita de mastocitose na pele:

4.I.I.I. Todos os doentes com lesões cutâneas sugestivas devem ser submetidos a biópsia cutânea.

4.I.I.2. A punção para administração do anestésico local não deve ser efetuada em área lesional e deve ser utilizada uma formulação que não contenha um vasoconstritor associado.

4.I.I.3. Os cortes devem ser corados com corantes panóticos, ou metacromáticos (ex: toluidina), e/ou técnicas de imuno-histoquímica, com anticorpos para a triptase e c-KIT (CDII7).

4.I.I.4. À microscopia pode observar-se um infiltrado mastocitário com 4 padrões possíveis ${ }^{40}$, sendo que nos primeiros 3 se verifica a presença de agregados com pelo menos 15 mastócitos, enquanto no quarto exemplo se verifica a presença de pelo menos 20 mastócitos por campo de grande ampliação (40x).

4.I.I.4.I. Infiltrado perivascular na derme papilar e reticular

4.I.I.4.2. Infiltrado em toalha na derme superficial

4.I.I.4.3. Infiltrado nodular

4.I.I.4.4. Infiltrado intersticial

4.I.I.5. O tipo de infiltrado cutâneo não tem qualquer valor preditivo para o envolvimento sistémico e está apenas parcialmente correlacionado com a morfologia macroscópica $^{40}$.

4.I.I.6. O diagnóstico de mastocitose cutânea pressupõe o cumprimento dos critérios diagnósticos para mastocitose cutânea (Quadro 3) e a ausência de critérios diagnósticos para mastocitose sistémica (Quadro 4).

4.I.I.7. No caso das crianças com mastocitose na pele, o estudo da medula óssea pode ser protelado, exceto em algumas situações particulares, tal como indicado no algoritmo de decisão, que consta da Figura I. A presença de sinais de doença hematológica (i.e. presença de citopenias e leucócitos imaturos no hemograma) está invariavelmente associada a formas sistémicas, pelo que se preconiza o estudo imediato da medula óssea ${ }^{4}$. A presença de organomegalias associada a triptase elevada e sintomatologia refratária à terapêutica intensiva está associada a
Quadro 3. Critérios de diagnóstico das mastocitoses cutâneas ${ }^{18}$.

\section{Critério major}

Lesões de mastocitose típicas associadas à presença de sinal de Darier*

\section{Critérios minor}

Número elevado de mastócitos em cortes de biópsia de lesões - infiltrado de mastócitos monomórficos, de grande tamanho (> 15 células/infiltrado), ou mais de 20 mastócitos isolados num campo de microscopia de grande ampliação $(\times 40)$

Mutação activante do KIT, em lesões cutâneas

O diagnóstico é estabelecido na presença do critério major e de, pelo menos, um critério minor ${ }^{18,48}$.

* O sinal de Darier pode estar ausente ou ser levemente positivo.

Quadro 4. Critérios de diagnóstico das mastocitoses sistémicas.

\section{Critério major}

Presença de agregados multifocais densos com 15 ou mais mastócitos na biópsia de medula óssea, ou em outros tecidos extracutâneos.

\section{Critérios minor}

Presença de mais de $25 \%$ de mastócitos de morfologia atípica, na biópsia de médula óssea, ou fusiformes, em infiltrados detetados em cortes de órgãos viscerais.

Deteção de uma mutação pontual do codão 816 do KIT na medula óssea, ou outro órgão extracutâneo.

Expressão aberrante de CD25 e/ou CD2 por mastócitos da medula óssea, ou de outro órgão extracutâneo.

Triptase sérica basal $\geq 20 \mathrm{ng} / \mathrm{mL}$ na ausência de outras patologias associadas com um aumento da triptase sérica (neoplasias mieloides não relacionadas)

O diagnóstico é estabelecido na presença do critério major e de pelo menos um critério minor, ou na presença de três critérios minor ${ }^{16}$.

formas sistémicas, pelo que nestes casos deve ser realizado o estudo da medula óssea ${ }^{14,42}$. Caso não existam organomegalias, a criança deve ser mantida em seguimento. Em situações em que a criança tenha necessidade de ser submetida a procedimento cirúrgico sob anestesia geral, deve ser efetuado estudo da medula óssea. $O$ estudo da medula óssea deve ser impreterivelmente realizado caso ocorra persistência das lesões no final da adolescência. 


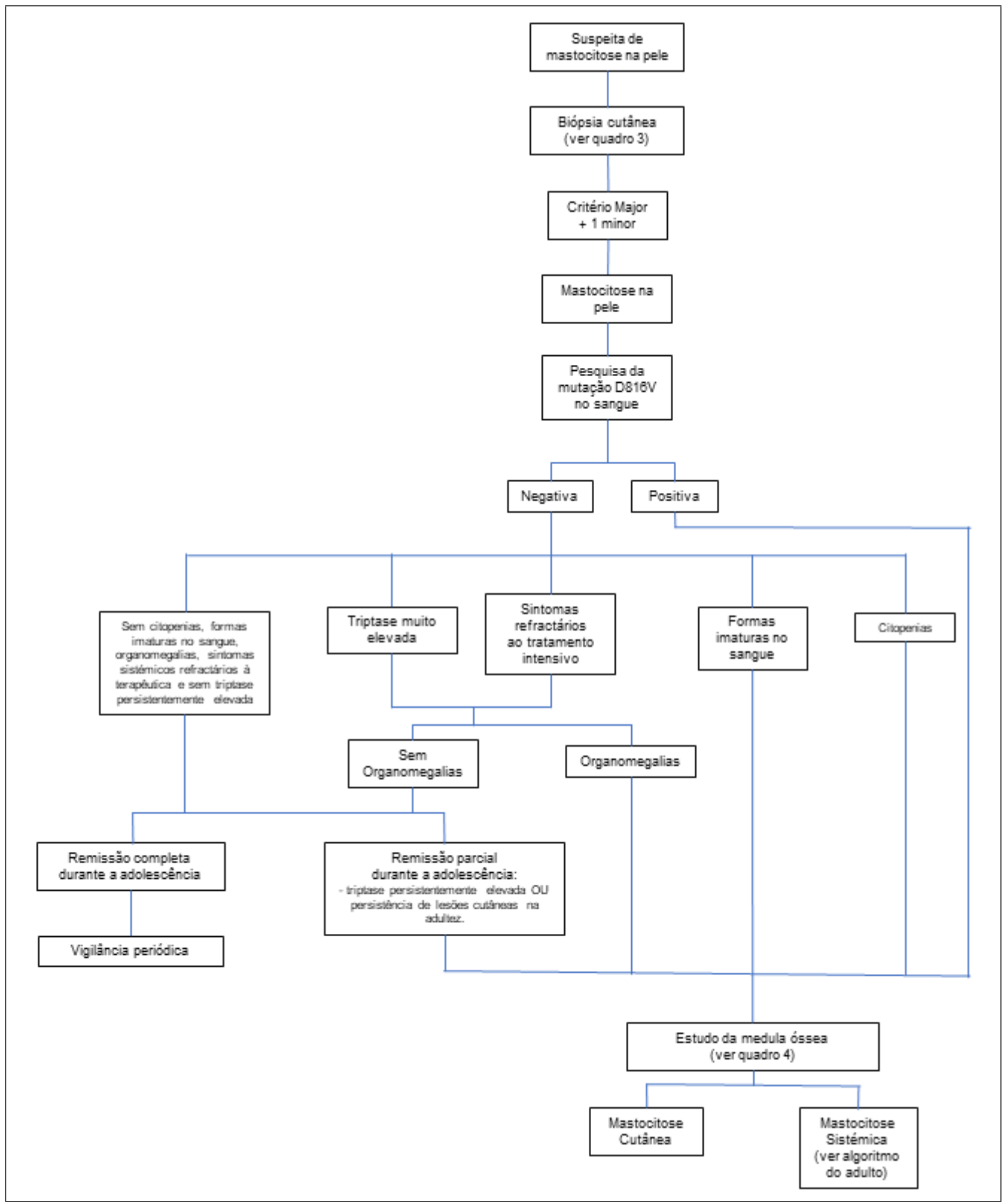

Figura I. Algoritmo para a investigação de doentes das idades pediátricas com suspeita de mastocitose 
4.I.I.8. Todos os adultos com mastocitose na pele devem ser submetidos a estudo da medula óssea (Figura 2):

4.I.I.8.I. Esfregaço de medula óssea, com corantes panóticos ou metacromáticos (Wright-Giemsa, ou azul-de-toluidina).

4.I.I.8.2. Biópsia de medula óssea, com corantes (hematoxilina-eosina) e técnicas de imuno-histoquímica (triptase, CDII7) ${ }^{43,44}$. Devem ser caracterizadas: celularidade, morfologia e número de mastócitos, presença de agregados mastocitários compactos, grau e tipo de infiltração mastocitária; presença de fibrose, esclerose óssea e agregados linfoides ${ }^{45}$.

4.I.I.8.2.I. Na maioria dos casos, os mastócitos aberrantes apresentam uma morfologia fusiforme, com citoplasma hipogranulado, com distribuição anormal e fusão granular. O núcleo pode ser ovoide, ou até bissegmentado (nas formas agressivas). Os agregados mastocitários podem ter uma distribuição multifocal, paratrabecular ou perivascular. A fibrose surge habitualmente nas formas agressivas ${ }^{43}$.

4.I.I.8.2.2. Nas mastocitoses sistémicas bem diferenciadas, os mastócitos apresentam características distintas: são habitualmente arredondados, mais volumosos e mais granulares do que os normais. Ao contrário do que habitualmente se verifica nas restantes formas sistémicas, podem não formar agregados (padrão intersticial) e apresentam, mais frequentemente, uma localização intertrabecular ${ }^{46}$.

4.I.I.8.3. Imunofenotipagem por citometria de fluxo ${ }^{47}$ :

4.I.I.8.3.I. O painel de marcadores deve incluir, no mínimo: CD45, CD34, CDI17, CD25, CD2, CD63, CD203c, CD69, CDI6, CD64, HLA-DR e CD30.

4.I.I.8.3.2. Os mastócitos normais são identificáveis pela grande expressão de CDII7 (c-KIT), CD45, FcદRI e CD203c. Os dois últimos são também expressos de forma considerável por basófilos, daí que não sejam utilizados rotineiramente.

4.I.I.8.3.3. Imunofenótipo das mastocitoses sistémicas (MS): na maioria dos casos $\mathrm{CD} 25^{++}, \mathrm{CD}^{+/}$.

4.I.I.8.3.4. Imunofenótipo das MS bem diferenciadas: CD25-/+dim, CD2-/+dim, CD $30^{+}$.
4.I.I.8.4. Pesquisa de mutações do KIT, idealmente, em amostras purificadas de mastócitos, de neutrófilos, monócitos, eosinófilos e linfócitos, por separação celular ativada por fluorescência:

4.I.I.8.4.I. Mutação D816V, preferencialmente, por PCR com oligonucleotídeos específicos de alelo (ASO-PCR).

4.I.I.8.5. Nas mulheres e caso não seja detetada qualquer mutação do KIT, a clonalidade dos mastócitos da medula óssea pode ser aferida através da determinação de inativação do cromossoma $X(X C I P)$ em amostras purificadas de mastócitos pelo human androgen receptor assay (HUMARA).

4.I.I.9. A suspeita de diagnóstico de mastocitose deve ser colocada em todos os doentes com história de anafilaxia ${ }^{48}$, independentemente da presença de lesões cutâneas e dos níveis de triptase sérica, de acordo com o algoritmo de decisão que consta da Figura 2.

4.I.I.9.I. Esta questão é particularmente relevante nos doentes com anafilaxia secundária a picada por himenópteros, associada a hipotensão/síncope e sem envolvimento mucocutâneo (isto é sem angioedema ou urticária), uma vez que a presença de mastocitose sistémica indolente (MSI), ou síndrome de ativação clonal de mastócitos, obriga, segundo diversos autores, a imunoterapia com veneno de himenópteros a longo prazo e requer cuidados específicos ${ }^{49,50}$.

4.I.I.9.2. Em doentes com anafilaxia deve ser utilizado o score da Red Española de Mastocitosis (REMA), que permite prever clonalidade com um valor preditivo positivo de $89 \%$ (Quadro 5) ${ }^{23,51}$.

4.I.I.9.3. Pode optar-se pela pesquisa da mutação do KIT no sangue periférico (para excluir a presença de mutação multilinhagem)

4.I.I.I0. Todos os doentes adultos, mas em particular aqueles com triptase $>25 \mathrm{ng} / \mathrm{mL}$, devem ser submetidos a estudos da medula óssea, uma vez que estes valores estão quase invariavelmente associados a mastocitose sistémica, ou outras neoplasias hematológicas com atingimento medular.

4.I.I.II. Raramente, as mastocitoses sistémicas podem apresentar-se como osteoporose, nomeadamente 


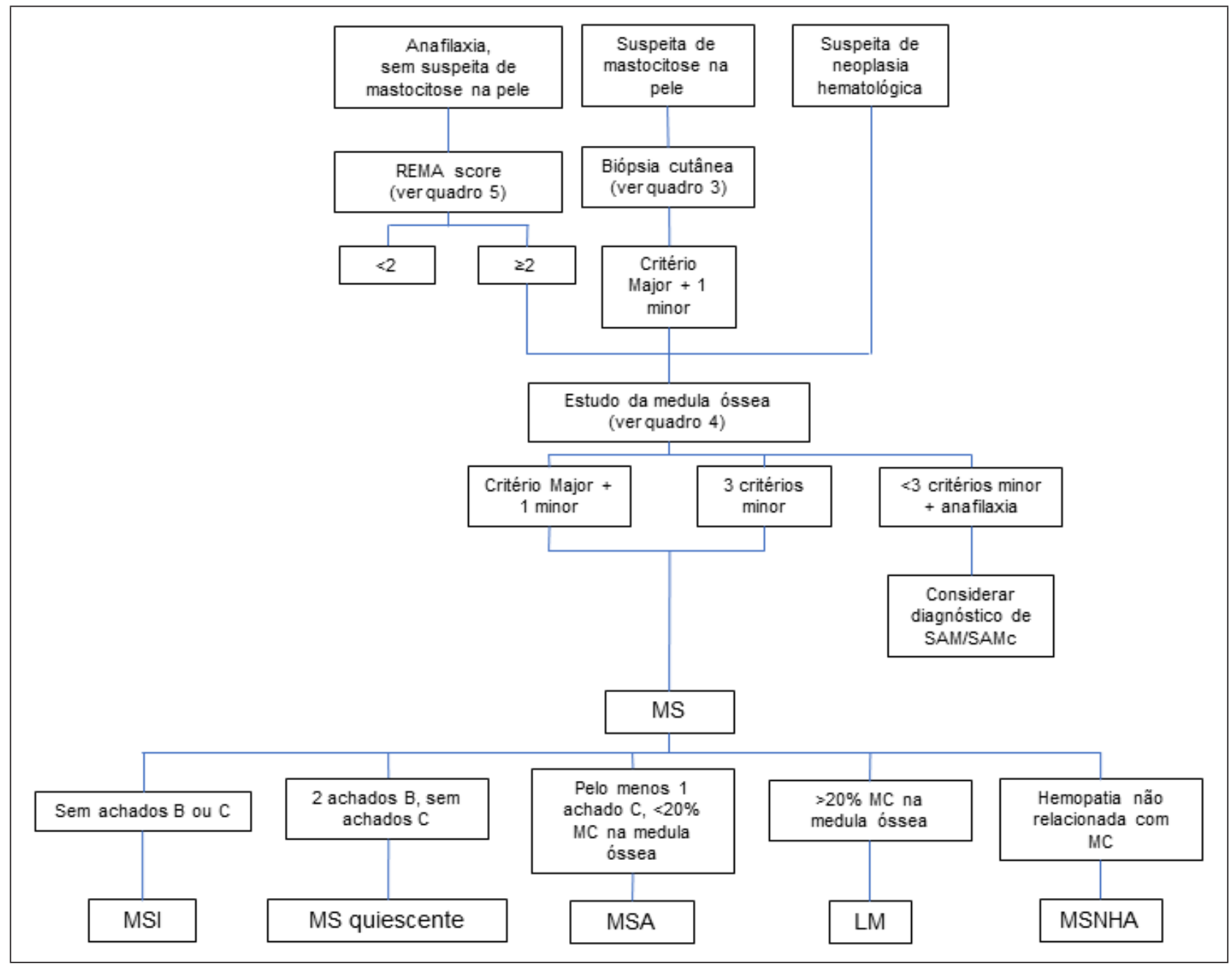

REMA - Red Española de Mastocitosis; SAM - Síndrome de activação mastocitária; SAMc - Síndrome de activação mastocitária clonal; MS - Mastocitose sistémica; MSI - Mastocitose sistémica indolente; MSA - Mastocitose sistémica agressiva, LM - Leucemia mastocitária; MSNHA - Mastocitose sistémica com neoplasia hematológica associada.

Figura 2. Algoritmo para a investigação de doentes adultos com suspeita de mastocitose

em jovens e na ausência de outros sinais/sintomas de libertação de mediadores mastocitários.

\section{Meios complementares de diagnóstico:}

5.I. Deve ser efetuado estudo analítico durante o procedimento diagnóstico e anualmente, com inclusão de:

\section{I.I. Hemograma completo}

5.1.2. Bioquímica: função renal, ionograma (incluindo cálcio, fósforo, magnésio e zinco), enzimas de citólise e função hepática; ferritina, vitamina BI2 e folatos
5.I.3. Imunologia: Triptase sérica basal, lgE total, $\beta-2-$ -microglobulina

5.2. Outros exames complementares de diagnóstico:

5.2.I. Pesquisa de organomegalias: Ecografia ou tomografia computorizada abdominal, a realizar durante $\circ$ procedimento diagnóstico e bianualmente.

5.2.2. Avaliação de patologia óssea:

5.2.2.I. Radiografia da coluna dorso-lombar, pélvis e ossos longos, no sentido de avaliar a presença de lesões 
Quadro 5. Sistema de pontuação utilizado pela Red Española de Mastocitosis (REMA) para previsão de patologia clonal dos mastócitos em doentes com anafilaxia ${ }^{23,48}$.

\begin{tabular}{|l|l|c|}
\hline \multicolumn{2}{|c|}{ Variáveis } & Pontuação \\
\hline \multirow{3}{*}{ Género } & Masculino & +1 \\
\cline { 2 - 3 } & Feminino & -1 \\
\hline \multirow{3}{*}{$\begin{array}{l}\text { Sintomas } \\
\text { clínicos }\end{array}$} & Sem urticária ou angioedema & +1 \\
\cline { 2 - 3 } & Urticária ou angioedema & -2 \\
\cline { 2 - 3 } & Pré-síncope e/ou síncope & +3 \\
\hline \multirow{3}{*}{ Triptase } & $<15 \mathrm{ng} / \mathrm{mL}$ & -1 \\
\cline { 2 - 3 } & $>25 \mathrm{ng} / \mathrm{mL}$ & +2 \\
\hline
\end{tabular}

Um total igual ou superior a 2 está associado a alta probabilidade de mastocitose sistémica.

osteoporóticas e osteoscleróticas, a realizar durante o procedimento diagnóstico, em adultos.

5.2.2.2. Densitometria óssea: durante o procedimento diagnóstico e bianualmente

5.3. Estudo imunoalergológico orientado pelas queixas e potenciais alergénios. Os doentes com história de anafilaxia/reações suspeitas de se poder tratar de anafilaxia devem ser referenciados à consulta de Imunoalergologia, para que sejam realizados testes cutâneos/determinação de lgE específicas e provas de provocação, de acordo com o caso em questão. A prevalência de atopia nas mastocitoses é semelhante à verificada na população geral ${ }^{39}$. Assim, em situação alguma devem ser pedidas IgE específicas de forma indiscriminada e sem critério clínico. Salienta-se a inutilidade de serem determinadas lgE específicas para venenos de himenópteros em amostras de sangue periférico de doentes que nunca sofreram picada por himenópteros.

\section{Critérios de diagnóstico:}

6.I. De acordo com a task-force de consenso formada pela Rede Europeia de Competência em Mastocitose (ECNM), a Academia Americana de Alergia, Asma e Imunologia (AAAAI) e a Academia Europeia de Alergologia e Imunologia Clínica (EAACI), a presença de envolvimento cutâneo por mastocitose é diagnosticada através da presença do critério major e de pelo menos um critério minor $^{|8,4|}$ (Quadro 3).

6.I.I. De acordo com os critérios de classificação da $\mathrm{OMS}^{16}$, revistos em 2016, as formas sistémicas de mastocitose são diagnosticadas através da presença do critério major na presença de um critério minor, ou da presença de pelo menos três critérios minor (Quadro 4).

6.I.2. As formas sistémicas com lesões cutâneas associadas, sem critérios de progressão ou agressividade, devem ser denominadas mastocitose sistémica indolente com envolvimento cutâneo. Da mesma forma, na ausência de lesões cutâneas devem ser denominadas mastocitoses sistémicas indolentes sem envolvimento cutâneo.

6.I.3. Na presença de uma forma sistémica e de uma neoplasia hematológica, devem ser denominadas mastocitoses sistémicas com neoplasia hematológica associada.

6.I.4. As formas de mastocitose sistémica quiescente (Smoldering systemic mastocytosis) são diagnosticadas em doentes com formas sistémicas através da presença de pelo menos dois achados $B$, na ausência de achados $C$ (Quadro 6).

6.I.4.I. As mastocitoses sistémicas agressivas (MSA) são diagnosticadas em doentes com formas sistémicas na presença de pelo menos um achado $C$, na ausência de leucemia de mastócitos. A MSA em transformação leucémica (MAS-t) é definida pela presença de MSA associada à infiltração de mastócitos em 5 a 19\% no esfregaço de medula óssea ${ }^{52}$.

6.I.4.2. A leucemia de mastócitos é diagnosticada na presença de, pelo menos, $20 \%$ de mastócitos na medula óssea e de, pelo menos, $10 \%$ de mastócitos no sangue periférico. Existe, porém, uma variante aleucémica que cursa com menos de $10 \%$ de mastócitos no sangue periférico.

6.I.4.3. As chamadas mastocitoses bem diferenciadas, ao contrário das restantes mastocitoses sistémicas, podem beneficiar da terapêutica com inibidores da cinase de tirosina com ação sobre o KIT (por exemplo: imatinib). Importa, assim, definir as diferenças desta variante infrequente: $95 \%$ dos casos tem início em idades pediátricas, 
Quadro 6. Achados clínicos e laboratoriais para classificação das formas de mastocitose sistémica quiescente (dois ou mais achados B; sem achados $\mathrm{C}$ ), ou agressivas (pelo menos um achado $C$, na ausência de leucemia de mastócitos) ${ }^{16}$

\section{Achados B}

Biópsia de medula óssea com mais de $30 \%$ de infiltração por mastócitos (agregados densos, focais) e triptase sérica $>200 \mathrm{ng} / \mathrm{mL}$.

Hipercelularidade medular óssea, com perda de adipócitos e sinais discretos de dismielopoiese, sem citopenias substanciais, ou critérios para síndrome mielodisplásica ou neoplasia mieloproliferativa segundo a OMS.

Hepatomegalia palpável sem disfunção hepática, e/ ou esplenomegalia palpável sem hiperesplenismo e/ou linfadenopatia palpável, ou com pelo $2 \mathrm{~cm}$ em exame de imagem (tomografia computorizada, ou ecografia).

\section{Achados C}

Citopenia(s): Contagem de neutrófilos $<1,000 / \mu \mathrm{L}$, ou Hemoglobina $<10 \mathrm{~g} / \mathrm{dL}$, ou contagem de plaquetas $<100,000 / \mu \mathrm{L}$

Hepatomegalia com ascite e disfunção hepática.

Esplenomegalia palpável, com hiperesplenismo associado.

Malabsorção com hipoalbuminemia e perda ponderal.

Lesões ósseas: osteólise de grandes dimensões, com fracturas patológicas.

Dano orgânico em outros sistemas, que condiciona risco de morte e que é causado por infiltração local de mastócitos nos tecidos.

apresentam um risco de progressão de cerca de $20 \%$, baixa/inexistente expressão de CD25 e/ou CD2, alta expressão de CD30, morfologia e fenótipo quase normal: mastócitos redondos, por vezes hipergranulares, ausência da mutação ativante do codão 816 do KIT; triptase, frequentemente, inferior a $20 \mathrm{ng} / \mathrm{mL}$.

7. Fatores desencadeantes: diversos fatores podem desencadear episódios de libertação de mediadores mastocitários nas mastocitoses.

7.I. Agentes físicos:

7.I.I. Calor-principal fator desencadeador em doentes em idades pediátricas.
7.I.2. Pressão e fricção lesional - os doentes em idades pediátricas com mastocitomas ou lesões nodulares podem desenvolver reações sistémicas após pesquisa do sinal de Darier ${ }^{18}$.

7.2. Alimentos:

7.2.I. A prevalência de anafilaxia provocada por alimentos é mais baixa nas mastocitoses do que na população geral ${ }^{23,37,39}$.

7.2.2. Não existe qualquer tipo de indicação para a evicção de qualquer tipo de alimentos nas mastocitoses, incluindo os chamados alimentos libertadores de histamina (carne de porco, chocolate, morangos, tomate, etc.) $)^{31}$. Excetuam-se, obviamente, os alimentos a que o doente tenha, previamente, reagido de forma consistente e reprodutível.

7.2.3. Os doentes com história de reações potencialmente provocadas por alimentos devem ser submetidos a avaliação imunoalergológica.

\subsection{Medicamentos:}

7.3.I. Anti-inflamatórios não esteroides (AINEs) - a maioria dos doentes com mastocitose tolera estes fármacos, pelo que não estão contraindicados nas mastocito$\operatorname{ses}^{53}$. Ainda assim, pelo risco de reações anafiláticas, a primeira administração destes fármacos deve ser feita em centros com experiência em provocações orais de fármacos. O paracetamol, o meloxicam e os inibidores seletivos da COX-2 podem ser utilizados com segurança na maioria dos doentes que não toleram AINEs tradicionais.

7.3.2. Opioides e opiáceos - alguns autores recomendam a não administração de opiáceos, nomeadamente morfina e codeína. Porém, o fentanil e derivados são considerados seguros nestes doentes ${ }^{54}$.

7.3.3. Relaxantes musculares utilizados em anestesia geral - podem ser utilizados agentes bloqueadores neuromusculares despolarizantes e não despolarizantes esteroides. Os agentes não despolarizantes do grupo das benzilisoquinolinas (atracúrio e mivacúrio) devem ser evitados 54 .

7.3.4. Anestésicos locais e anestesia locorregional - os anestésicos locais do grupo amida são considerados se- 
guros, desde que seja realizada pré-medicação (especificado no ponto 9.1 $)^{55}$.

7.3.5. Antagonistas do sistema nervoso simpático e agonistas do sistema nervoso parassimpático - a administração de fármacos como os betabloqueadores deve ser bem ponderada, em doentes que apresentem anafilaxias de repetição, pelo risco de antagonismo dos efeitos da adrenalina. As mastocitoses não são contraindicações absolutas para a utilização destes fármacos ${ }^{10}$.

7.3.6. Soluções parentéricas coloides utilizadas em casos de hipotensão, ou hipovolemia, como o dextrano, devem ser evitados ${ }^{10}$.

7.3.7. Interferão- $\alpha$, claridribina - bastante utilizados como citorredutores. Podem ativar os mastócitos, pelo que a sua administração deve ser feita sob vigilância ${ }^{10}$.

7.3.8. Vacinas - não existe qualquer tipo de contraindicação para o cumprimento do Plano Nacional de Vacinação nos doentes com mastocitose ${ }^{56}$. No sentido de prevenir reações, deve ser administrada pré-medicação (ver 9.I.I) $)^{49}$.

7.4. Venenos:

7.4.I. Himenópteros

7.4.2. Ofídeos

7.5. Fatores endógenos

7.5.I. Stress emocional e ansiedade

7.5.2. Dor

\section{Tratamento:}

8.I. Evicção dos fatores desencadeadores para cada doente. Todos os doentes devem ser portadores de documentação em que estejam especificados, de forma clara e objetiva, os fatores que neles desencadeiam a libertação de mediadores mastocitários. Não existe qualquer tipo de indicação para a evicção indiscriminada de potenciais fatores desencadeantes da ativação mastocitária, sem que se verifique a presença de reações reprodutíveis de libertação de mediadores após exposição ao referido fator.
Nível de evidência: baixo. Força da recomendação: fraca - baseada na opinião de especialistas.

8.2. Tratamento antimediador individualizado:

8.2.I. Deve ser instituído cromoglicato de sódio per os (PO) a todos os doentes com mastocitose, incluindo assintomáticos ${ }^{57-63}$. Em Portugal, o cromoglicato de sódio não se encontra comercializado em farmácia comunitária, pelo que se recomenda a sua utilização como fórmula magistral em solução (nas crianças) - $12-15 \mathrm{mg} / \mathrm{kg} / \mathrm{dia}$ dividida em 3 administrações diárias -, ou em cápsulas de $200 \mathrm{mg}$ (nos adolescentes a partir dos 12 anos e adultos) - até 6 cápsulas $/ \mathrm{dia}^{58}$.

Nível de evidência: moderado. Força da recomendação: moderada - baseada em ensaios clínicos, com número reduzido de casos.

8.2.2. Nas formas cutâneas estritas pode ser instituído cromoglicato de sódio tópico, caso existam apenas sintomas cutâneos localizados e, nomeadamente, em doentes pediátricos ${ }^{14,64}$.

Nível de evidência: baixo. Força da recomendação: fraca - baseada na opinião de especialistas.

8.2.3. Caso a terapêutica com cromoglicato de sódio seja insuficiente para controlo dos sinais e sintomas decorrentes da libertação de mediadores mastocitários, devem ser instituídos anti-histamínicos HI. Pode ser necessária a instituição de várias tomas diárias. Alguns doentes, nomeadamente com sintomas gastrointestinais, beneficiam da adição de anti-histamínicos $\mathrm{H} 2$ à sua terapêutica de base ${ }^{41}$.

Nível de evidência: baixo. Força da recomendação: fraca - baseada na opinião de especialistas.

8.2.4. Sintomas gastrointestinais: em doentes com refluxo e/ou pirose, não respondentes a anti-histamínicos $\mathrm{H} 2$, devem ser instituídos inibidores da bomba de protões. Cólicas abdominais e/ou diarreia refratários ao cromoglicato e anti-histamínicos $\mathrm{HI}$ respondem frequentemente ao montelucaste. $O$ cetotifeno pode também ser efetivo nestes casos, mas o seu efeito sedativo e reduzida semivida dificultam a adesão terapêutica ${ }^{59}$. Está descrita a melhoria de sintomas gastrointestinais e, em particular, da dor abdominal com glucocorticoides em doses baixas, nomeadamente 
nas crianças ${ }^{14}$. A presença de sintomatologia gastrointestinal aguda/com agravamento inexplicável/refratária à terapêutica carece de exclusão de outras causas, podendo ser necessária avaliação por gastroenterologia ${ }^{65}$.

Nível de evidência: baixo. Força da recomendação: fraca - baseada na opinião de especialistas.

8.2.5. Angioedema: os doentes com angioedema refratário ao cromoglicato de sódio e anti-histamínicos $\mathrm{HI}$ que tolerem AINEs podem beneficiar de terapêutica com ácido acetilsalicílico em doses elevadas $(\mathrm{I} \mathrm{g} / \mathrm{dia})^{59}$. Podem também ser utilizados glucocorticoides, nomeadamente nas crianças ${ }^{14}$.

Nível de evidência: baixo. Força da recomendação: fraca - baseada na opinião de especialistas.

8.2.6. Malabsorção: cromoglicato de sódio ${ }^{59}$. Ponderar glucocorticoides em doses baixas, se não houver melhoria do ponto de vista analítico ${ }^{14}$.

Nível de evidência: baixo. Força da recomendação: fraca - baseada na opinião de especialistas.

8.2.7. Osteopenia/osteoporose: cromoglicato de sódio ${ }^{66}$. Em doentes com défice de vitamina $D$ deve ser feita suplementação com associações com cálcio e com controlo estrito de calcemia e calciúria ${ }^{59}$. A osteoporose deve ser tratada com bisfosfonatos.

Nível de evidência: moderado. Força da recomendação: moderada - baseada na opinião de especialistas e em ensaios clínicos realizados em osteoporose não secundária a mastocitose.

8.2.8. Esclerose óssea: cromoglicato de sódio ${ }^{10}$.

Nível de evidência: baixo. Força da recomendação: fraca - baseada na opinião de especialistas.

8.2.9. Sintomatologia refratária: em situações em que a terapêutica previamente descrita e em associação (cromoglicato de sódio + anti-histamínico HI + anti-histamínico $\mathrm{H} 2$ + montelucaste) não seja suficiente para controlar a clínica decorrente da libertação de mediadores mastocitários, pode ser efetuada prova terapêutica com fototerapia com PUVA ${ }^{67}$.

Nível de evidência: baixo. Força da recomendação: fraca - baseada na opinião de especialistas e em estudos observacionais retrospetivos.
8.2.10. Mastocitose com anafilaxia associada: $O$ tratamento de eleição da anafilaxia, nas mastocitoses, não difere do preconizado para a população geral ${ }^{15}$ : o alergénio deve ser removido, se possível, e deve ser administrada adrenalina (Img/mL) 0,3-0,5 mg IM, cuja administração deve ser repetida com 5-15 minutos de intervalo, se necessário. Todos os doentes com mastocitose e com história de anafilaxia devem ser portadores de um dispositivo autoinjector de adrenalina. Nas situações em que se verifique a presença de episódios de anafilaxia de repetição, refratários ao tratamento antimediador de base, deve ser ponderada a utilização de anticorpos monoclonais anti-lgE (omalizumab) ${ }^{68}$. Se associados a stress importante deve ser instituído tratamento psiquiátrico/ /psicoterapêutico, com reforço de estratégias de coping e gestão de stress ${ }^{33,35}$. A doxepina tem sido referida como efetiva nos casos que cursam com episódios de libertação maciça frequentes, especialmente quando associados a sintomatologia neuropsiquiátrica.

Nível de evidência: baixo. Força da recomendação: fraca - baseado na opinião de especialistas.

8.2.II Sintomatologia induzida pelo stress e sintomatologia do sistema nervoso central - tal como indicado no ponto anterior, deve ser instituído tratamento psiquiátrico/psicoterapêutico, com reforço de estratégias de coping e gestão de stress a doentes cujos sintomas basais sejam induzidos/agravados pelo stress ${ }^{33}, 35$. Não existe consenso no que diz respeito ao tratamento das manifestações do sistema nervoso central. Estão descritas melhorias com a terapêutica com cromoglicato de sódio ${ }^{57}$, anti-histamínicos $\mathrm{HI}$, montelucaste, antidepressivos, ou psicoterapia ${ }^{65}$.

8.3. Tratamento citorredutor:

8.3.I. Desnecessário na maioria das situações, devendo ser evitado nos doentes com MSI e mastocitose sistémica quiescente (smoldering) $)^{17,41,69-71}$.

8.3.2. O interferão- $\alpha$ e a cladribina são os citotóxicos mais utilizados nas mastocitoses sistémicas avançadas, mas apresentam uma taxa de resposta relativamente modesta, de 20 a $30 \%$. 
8.3.3. O imatinib, um inibidor da cinase de tirosina, tem indicação apenas nas mastocitoses sistémicas bem diferenciadas ${ }^{72}$.

Nível de evidência: moderado. Força da recomendação: moderada - baseada em ensaio clínico de fase IV.

8.3.4. A midostaurina, ao contrário do imatinib, tem uma ação inibidora do KIT com a mutação D8I6V e tem vindo a ser utilizada, com resultados promissores, nas mastocitoses avançadas ${ }^{73-75}$ e mesmo em MSI muito sintomáticas ${ }^{76}$.

Nível de evidência: moderado. Força da recomendação: moderada - baseada em ensaios clínicos de fase II.

9. Profilaxia: há diversas medidas que podem prevenir reações de libertação de mediadores mastocitários:

9.1. Pré-medicação:

9.I.I. Vacinação, procedimentos de baixo risco, anestesia local/locorregional para pequena cirurgia/cirurgia oral, procedimentos endoscópicos, procedimentos médicos que causem stress a doentes suscetíveis:

9.I.I.I. Anti-histamínico HI: Clemastina: 2 mg, por via endovenosa (EV), ou outro anti-histamínico $\mathrm{HI}, \mathrm{PO}$, I hora antes da indução anestésica/procedimento. Nas crianças, a dose deve ser ajustada de acordo com o peso.

9.I.I.2. Anti-histamínico H2: Ranitidina: $2 \mathrm{mg} / \mathrm{kg}$ PO na criança/adolescente até aos 16 anos; $150 \mathrm{mg} P O$, no adulto e adolescentes a partir dos 16 anos, ou $1 \mathrm{mg} / \mathrm{kg}$ EV na criança/adolescente até aos 16 anos; $100 \mathrm{mg}$ EV no adulto e adolescentes a partir dos 16 anos, I hora antes da indução anestésica/procedimento.

9.I.I.3. Benzodiazepinas (por exemplo, diazepam $5 \mathrm{mg}$ ) PO, I hora antes da indução anestésica/procedimento nos adultos em que seja previsível que a intervenção possa desencadear ansiedade. Nas crianças, a sedação deve ser ponderada de acordo com a necessidade da mesma e, eventualmente, com a avaliação do caso feita pelo anestesista.

Nível de evidência: baixo. Força da recomendação: fraca, baseada na opinião de especialistas.

9.1.2. Parto e procedimentos imagiológicos que requeiram meios de contraste iodados:
9.I.2.I. Anti-histamínico HI: clemastina: $2 \mathrm{mg} \mathrm{EV}$, ou outro anti-histamínico HI PO, I hora antes do procedimento.

9.1.2.2. Anti-histamínico H2: ranitidina: $2 \mathrm{mg} / \mathrm{kg} P O$, na criança/adolescente até aos 16 anos; $150 \mathrm{mg} P O$, no adulto e adolescentes a partir dos 16 anos; ou $1 \mathrm{mg} / \mathrm{kg}$ EV na criança/adolescente até aos 16 anos; $100 \mathrm{mg}$ EV no adulto e adolescentes a partir dos 16 anos, I hora antes do procedimento.

9.1.2.3. Prednisona: I mg/kg PO, ou dose equivalente de metilprednisolona EV I3, 7 e I hora antes da administração. Estas três doses são opcionais, sendo que podem ser efetuadas modificações se não existirem antecedentes de libertação aguda de mediadores provocada pela administração de produtos de contraste radiológico.

9.1.2.4. Montelucaste: I comprimido ( $4 \mathrm{mg}$ dos 2 aos 5 anos, $5 \mathrm{mg}$ após os 5 anos e até aos $15,10 \mathrm{mg}$ após os 15 anos) 24 horas antes e I hora antes do procedimento - apenas nos casos em que haja história de episódios de libertação de mediadores provocada pela administração de produtos de contraste radiológico.

Nível de evidência: baixo. Força da recomendação: fraca, baseada na opinião de especialistas.

9.1.3. Procedimentos cirúrgicos major ou doentes com história de reações graves durante procedimentos/após indução anestésica.

9.I.3.I. Anti-histamínico HI: clemastina: $2 \mathrm{mg}$, por via endovenosa (EV), ou outro anti-histamínico $\mathrm{HI}, \mathrm{PO}, \mathrm{I}$ hora antes da indução anestésica. Nas crianças, a dose deve ser ajustada de acordo com o peso.

9.1.3.2. Anti-histamínico H2: ranitidina: $2 \mathrm{mg} / \mathrm{kg} P O$ na criança/adolescente até aos 16 anos; $150 \mathrm{mg} P O$, no adulto e adolescentes a partir dos 16 anos, ou $1 \mathrm{mg} / \mathrm{kg}$ EV na criança/adolescente até aos 16 anos; 100 mg EV no adulto e adolescentes a partir dos 16 anos, I hora antes do procedimento.

9.1.3.3. Benzodiazepinas (por exemplo, diazepam 5 $\mathrm{mg}$ ) PO, ou EV I hora antes do procedimento anestésico, nos adultos em que seja previsível que a intervenção possa desencadear ansiedade. Nas crianças, a sedação deve ser 
ponderada de acordo com a necessidade da mesma e, eventualmente, com a avaliação do caso feita pelo anestesista.

9.I.3.4. Prednisona: I mg/kg PO, ou dose equivalente de metilprednisolona EV 12 e I hora antes do procedimento.

Nível de evidência: baixo. Força da recomendação: fraca, baseada na opinião de especialistas.

\section{Gravidez:}

10.I.I.I. As mastocitoses não são contraindicações para a gravidez ${ }^{77,78}$.

10.I.I.2. De forma semelhante ao que se verifica na asma, cerca de I/3 das doentes mantém um estado clínico sobreponível, enquanto I/3 sofre agravamento e um I/3 melhora durante a gravidez ${ }^{78}$.

10.I.I.3. No que diz respeito ao tratamento antimediador na gravidez:

10.I.I.3.I. Anti-histamínicos HI: podem ser utilizados cetirizina, loratadina e desloratadina 77,79 .

10.I.I.3.2. Anti-histamínicos $\mathrm{H} 2$ : podem ser utilizados ranitidina, ou famotidina ${ }^{77,80}$.

I0.I.I.3.3. Cromoglicato de sódio: pode ser utilizado durante a gravidez ${ }^{77}$.

I0.I.I.3.4. Anti-IgE (omalizumab): pode ser utilizado durante a gravidez ${ }^{77}$

10.I.I.3.5. Glucocorticoides: a sua utilização deve ser evitada de forma continuada, pelo menos durante o primeiro trimestre da gravidez ${ }^{77}$.

I0.I.I.3.6. Montelucaste: pode ser utilizado durante a gravidez ${ }^{77}$.

10.I.I.3.7. Adrenalina: pode ser utilizada durante a gravidez ${ }^{77}$.

10.I.I.4. Especificidades da anafilaxia durante a gravidez:

10.I.I.4.I. A terapêutica geral da anafilaxia na grávida é semelhante à população geral: o alergénio deve ser removido, se possível, e deve ser administrada adrenalina (Img/mL) 0,3-0,5 mg IM, cuja administração deve ser repetida com 5-15 minutos de intervalo, se necessário.

10.I.I.4.2. Após administração de adrenalina, a grávida não deve voltar rapidamente ao ortostatismo, por risco de síndrome do ventrículo vazio. Deve manter-se em decúbito lateral esquerdo, para prevenir compressão dos grandes vasos pelo útero grávido.

10.I.I.4.3. Deve ser administrado $\mathrm{NaCl}$ a $0,9 \%$ para manutenção de valores de pressão arterial sistólica superiores a $90 \mathrm{mmHg}$, com o propósito de manter uma perfusão placentária adequada.

I0.I.I.4.4. Logo que possível deve ser efetuada monitorização fetal.

I0.I.I.4.5. Podem ser administrados anti-histamínicos HI (ver 9l.4.3.I.) e glucocorticoides (por exemplo, metilprednisolona I $\mathrm{mg} / \mathrm{kg} \mathrm{EV}$ )

10.I.I.4.6. Deve ser administrada oxigenoterapia, se ocorrer dessaturação e salbutamol por via inalatória, se se verificar broncospasmo refratário à adrenalina. Deve ser preparado tubo endotraqueal, para a eventualidade de necessidade de entubação.

\section{CONCLUSÕES}

A abordagem clínica das mastocitoses carece de cuidados específicos e de uma complementaridade entre especialidades, no que diz respeito ao seu diagnóstico, tratamento e seguimento.

O diagnóstico requer sempre uma confirmação histopatológica, quer estejamos na presença de suspeita de mastocitose na pele/cutânea, ou de mastocitoses sistémicas. De salientar que, no adulto, a presença de mastocitose sistémica deve ser sempre excluída em doentes com mastocitose na pele. As mastocitoses sistémicas sem envolvimento cutâneo inauguram, geralmente, com quadros de anafilaxia, pelo que a sua existência deve estar sempre presente aquando da investigação imunoalergológica da anafilaxia.

A maioria dos doentes apresentará sintomas decorrentes da libertação de mediadores mastocitários quando exposto a um ou mais dos chamados fatores desencadeantes da ativação mastocitária (calor, frio, venenos, fármacos como os AINEs, ou os opiáceos/opioides). 
Ainda assim, não existe indicação formal para evicção de todos estes fatores, apenas daqueles a que o doente, efetivamente reagir.

Dada a complexidade destas doenças e multiplicidade de possíveis fatores desencadeantes de sintomas decorrentes da libertação de mediadores mastocitários, é importante que todos os doentes sejam portadores de documentação sobre a sua doença e sobre os fatores a evitar. O tratamento deve ser individualizado a cada doente e à sua sintomatologia específica, podendo incluir cromoglicato de sódio, anti-histamínicos $\mathrm{HI}$ e $\mathrm{H} 2$, entre outros. Devem, também, ser fornecidos aos doentes esquemas de pré-medicação a realizar antes de procedimentos cirúrgicos, parto e utilização de meios de contraste iodados.

\section{Conflito de interesses}

Os autores declaram que não existem conflitos de interesse.

\section{AGRADECIMENTOS}

Os autores agradecem ao Doutor Ivan Alvarez-Twoze, Instituto de Estudios de Mastocitosis de Castilla-la-Mancha, Toledo, Espanha, pela revisão crítica deste texto.

\section{Contacto:}

Tiago Azenha Rama,

Serviço de Imunoalergologia - Centro Hospitalar

Universitário de São João,

Alameda Prof. Hernâni Monteiro,

4200-319 Porto, Portugal.

E-mail: tiagorama@gmail.com

\section{REFERÊNCIAS}

I. Valent P, Akin C, Metcalfe DD. Mastocytosis: 2016 updated WHO classification and novel emerging treatment concepts. Blood 2017;129(II):1420-7.

2. Cohen SS, Skovbo S, Vestergaard H, Kristensen T, Moller M, Bindslev-Jensen $\mathrm{C}$, et al. Epidemiology of systemic mastocytosis in Denmark. Br J Haematol 2014;166(4):52I-8.
3. van Doormaal JJ, Arends S, Brunekreeft KL, van der Wal VB, Sietsma J, van Voorst Vader PC, et al. Prevalence of indolent systemic mastocytosis in a Dutch region. J Allergy Clin Immunol 20|3;|3I(5):|429-3I el.

4. Kitamura Y, Oboki K, Ito A. Molecular mechanisms of mast cell development. Immunol Allergy Clin North Am 2006;26(3):387-405; v.

5. Galli SJ, Tsai M, Wershil BK. The c-kit receptor, stem cell factor, and mast cells. What each is teaching us about the others. Am J Pathol 1993;142(4):965-74.

6. Theoharides TC, Valent P, Akin C. Mast cells, mastocytosis, and related disorders. N Engl J Med 2015;373(2):163-72.

7. Theoharides TC, Kempuraj D, Marchand J, Tzianoumis L, Vasiadi M, Katsarou-Katsari A, et al. Urticaria pigmentosa associated with acute stress and lesional skin mast-cell expression of CRF-RI. Clin Exp Dermatol 2009;34(5):el63-6.

8. Theoharides TC. Mast cells and stress-a psychoneuroimmunological perspective. J Clin Psychopharmacol 2002;22(2):103-8.

9. Broesby-Olsen S, Dybedal I, Gulen T, Kristensen TK, Moller MB, Ackermann L, et al. Multidisciplinary management of mastocytosis: Nordic expert group consensus. Acta Derm Venereol 2016;96(5):602-12.

10. De la Hoz B, Gonzalez de Olano D, Alvarez I, Sanchez L, Nunez $\mathrm{R}$, Sanchez I, et al. [Guidelines for the diagnosis, treatment and management of mastocytosis]. An Sist Sanit Navar 2008;3I(I):II-32.

II. Lange M, Flisiak I, L. Kapińska-Mrowiecka M, Kaszuba A, Maj J, Rudnicka L, et al. Mastocytosis. Diagnostic and therapeutic recommendations of the Polish Dermatological Society. Dermatology Review/Przegląd Dermatologiczny 2018;105(3):358-83.

12. Valent P, Aberer E, Beham-Schmid C, Fellinger C, Fuchs W, Gleixner KV, et al. Guidelines and diagnostic algorithm for patients with suspected systemic mastocytosis: a proposal of the Austrian competence network (AUCNM). Am J Blood Res 2013;3(2):174-80 .

13. Bonadonna P, Pagani M, Aberer W, Bilo MB, Brockow K, Oude Elberink $\mathrm{H}$, et al. Drug hypersensitivity in clonal mast cell disorders: ENDA/EAACI position paper. Allergy 2015;70(7):755-63.

14. Castells M, Metcalfe DD, Escribano L. Diagnosis and treatment of cutaneous mastocytosis in children: practical recommendations. Am J Clin Dermatol 20II;12(4):259-70.

15. Direcção Geral de Saúde. Anafilaxia: Abordagem Clínica. Norma Orientação Clínica n. ${ }^{\circ}$ 014/2012, atualizada a 18/12/2014 (2014) I-20.

16. Horny H, Akin C, Arber D, et al. Mastocytosis. 2016. In: World Health Organization (WHO) classification of tumours. Pathology \& Genetics. Tumours of Haematopoietic and Lymphoid Tissues. [Internet]. Lyon, France: IARC Press.

17. Escribano L, Akin C, Castells M, Orfao A, Metcalfe DD. Mastocytosis: current concepts in diagnosis and treatment. Ann Hematol 2002;8I(I2):677-90. 
18. Hartmann K, Escribano L, Grattan C, Brockow K, Carter MC, Alvarez-Twose I, et al. Cutaneous manifestations in patients with mastocytosis: Consensus report of the European Competence Network on Mastocytosis; the American Academy of Allergy, Asthma \& Immunology; and the European Academy of Allergology and Clinical Immunology. J Allergy Clin Immunol 2016;137(I): 35-45.

19. Correia O, Duarte AF, Quirino P, Azevedo R, Delgado L. Cutaneous mastocytosis: Two pediatric cases treated with topical pimecrolimus. Dermatol Online J 2010;16(5):8.

20. Valent P, Escribano L, Broesby-Olsen S, Hartmann K, Grattan C, Brockow K, et al. Proposed diagnostic algorithm for patients with suspected mastocytosis: a proposal of the European Competence Network on Mastocytosis. Allergy 2014;69(10):1267-74.

21. Zanotti R, Bonadonna P, Bonifacio M, Artuso A, Schena D, Rossini $\mathrm{M}$, et al. Isolated bone marrow mastocytosis: an underestimated subvariant of indolent systemic mastocytosis. Haematologica 2011;96(3):482-4.

22. Georgin-Lavialle S, Lhermitte L, Dubreuil P, Chandesris MO, Hermine O, Damaj G. Mast cell leukemia. Blood 2013;12I(8):I285-95 .

23. Alvarez-Twose I, Gonzalez de Olano D, Sanchez-Munoz L, Matito A, Esteban-Lopez MI, Vega A, et al. Clinical, biological, and molecular characteristics of clonal mast cell disorders presenting with systemic mast cell activation symptoms. J Allergy Clin Immunol 20I0;125(6):1269-78 e2.

24. Rama TA, Corte-Real I, Gomes PS, Escribano L, Fernandes MH. Mastocytosis: oral implications of a rare disease. J Oral Pathol Med 20II;40(6):44I-50.

25. Rama T, Morgado J, Alvarez-Twose I, Matito A, Sanchez-Muñoz $\mathrm{L}$, Moreira A, et al. Bone marrow mast cell burden influences the severity of periodontal disease, in mastocytosis. Abstracts TPS. Allergy 2018;73(SI05):370-702.

26. Escribano L, Alvarez-Twose I, Sanchez-Munoz L, Garcia-Montero A, Nunez R, Almeida J, et al. Prognosis in adult indolent systemic mastocytosis: a long-term study of the spanish network on mastocytosis in a series of 145 patients. J Allergy Clin Immunol 2009;124(3):5I4-2I.

27. Rossini M, Zanotti R, Orsolini G, Tripi G, Viapiana O, Idolazzi L, et al. Prevalence, pathogenesis, and treatment options for mastocytosis-related osteoporosis. Osteoporos Int 2016.

28. Rossini M, Zanotti R, Viapiana O, Tripi G, Orsolini G, Idolazzi L, et al. Bone involvement and osteoporosis in mastocytosis. Immunol Allergy Clin North Am 2014;34(2):383-96.

29. Barete S, Assous N, de Gennes C, Grandpeix C, Feger F, Palmerini $\mathrm{F}$, et al. Systemic mastocytosis and bone involvement in a cohort of 75 patients. Ann Rheum Dis 2010;69(10):1838-4I.

30. van der Veer E, van der Goot W, de Monchy JG, Kluin-Nelemans $\mathrm{HC}$, van Doormaal JJ. High prevalence of fractures and osteopo- rosis in patients with indolent systemic mastocytosis. Allergy 20I2;67(3):43I-8.

3I. Brockow K, Jofer C, Behrendt H, Ring J. Anaphylaxis in patients with mastocytosis: a study on history, clinical features and risk factors in 120 patients. Allergy 2008;63(2):226-32.

32. Gonzalez-de-Olano D, Matito A, Sanchez-Lopez P, Sanchez-Munoz L, Morgado JM, Teodosio C, et al. Mast cell-related disorders presenting with Kounis syndrome. Int J Cardiol 20I2;16I(I):56-8.

33. Moura DS, Georgin-Lavialle S, Gaillard R, Hermine O. Neuropsychological features of adult mastocytosis. Immunol Allergy Clin North Am 2014;34(2):407-22.

34. Georgin-Lavialle S, Moura DS, Bruneau J, Chauvet-Gelinier JC, Damaj G, Soucie E, et al. Leukocyte telomere length in mastocytosis: Correlations with depression and perceived stress. Brain Behav Immun 2013.

35. Moura DS, Sultan S, Georgin-Lavialle S, Barete S, Lortholary O, Gaillard R, et al. Evidence for cognitive impairment in mastocytosis: prevalence, features and correlations to depression. PLoS One 2012;7(6):e39468.

36. Smith JH, Butterfield JH, Cutrer FM. Primary headache syndromes in systemic mastocytosis. Cephalalgia 20II;3I(I5):I522-3I.

37. Matito A, Alvarez-Twose I, MorgadoJM, Sanchez-Munoz L, Orfao A, Escribano L. Anaphylaxis as a clinical manifestation of clonal mast cell disorders. Curr Allergy Asthma Rep 2014;14(8):450.

38. Escribano L, Orfao A. Anaphylaxis in mastocytosis. In: Castells MC (Ed.). Anaphylaxis and hypersensitivity reactions. New York, $201 \mathrm{I}$.

39. González de Olano D, de la Hoz Caballer B, Núñez López R, Sánchez Muñoz L, Cuevas Agustín M, Diéguez MC, et al. Prevalence of allergy and anaphylactic symptoms in 210 adult and pediatric patients with mastocytosis in Spain: a study of the spanish network on mastocytosis (REMA). Clin Exp Allergy 2007;37(10):1547-55.

40. Wolff K, Komar M, Petzelbauer P. Clinical and histopathological aspects of cutaneous mastocytosis. Leuk Res 200I;25(7):5I9-28.

4I. Valent P, Akin C, Escribano L, Födinger M, Hartmann K, Brockow $\mathrm{K}$, et al. Standards and standardization in mastocytosis: consensus statements on diagnostics, treatment recommendations and response criteria. Eur J Clin Invest 2007;37(6):435-53.

42. Carter MC, Clayton ST, Komarow HD, Brittain EH, Scott LM, Cantave D, et al. Assessment of clinical findings, tryptase levels, and bone marrow histopathology in the management of pediatric mastocytosis. J Allergy Clin Immunol 2015;136(6):1673-9 e3.

43. Horny HP, Valent P. Diagnosis of mastocytosis: general histopathological aspects, morphological criteria, and immunohistochemical findings. Leuk Res 200I;25(7):543-5I.

44. Li CY. Diagnosis of mastocytosis: value of cytochemistry and immunohistochemistry. Leuk Res 200I;25(7):537-4I.

45. Escribano L, Garcia-Montero A, Sanchez-Muñoz L, Teodosio C, Alvarez-Twose I, Jara-Acevedo M, et al. Diagnosis of adult mastocy- 
tosis: role for bone marrow analysis. In: Kottke-Marchant K, Davis B (Eds.). Laboratory Hematology Practice: Wiley-Blackwell 2012.

46. Alvarez-Twose I, Jara-Acevedo M, Morgado JM, Garcia-Montero A, Sanchez-Munoz L, Teodosio C, et al. Clinical, immunophenotypic, and molecular characteristics of well-differentiated systemic mastocytosis. J Allergy Clin Immunol 2016;137(I):168-78 el.

47. Teodosio C, Garcia-Montero AC, Jara-Acevedo M, Sanchez-Munoz L, Alvarez-Twose I, Nunez R, et al. Mast cells from different molecular and prognostic subtypes of systemic mastocytosis display distinct immunophenotypes. J Allergy Clin Immunol 2010;125(3):719-26, 26 el-26 e4.

48. Mota I, Pereira AM, Pereira C, Tomaz E, Ferreira MB, Sabino F, et al. Approach and registry of anaphylaxis in Portugal. Acta medica portuguesa 2015;28(6):786-96.

49. Gonzalez-de-Olano D, Matito A, Orfao A, Escribano L. Advances in the understanding and clinical management of mastocytosis and clonal mast cell activation syndromes. Fl000Res. 2016;5:2666.

50. Bonadonna P, Zanotti R, Pagani M, Bonifacio M, Scaffidi L, Olivieri E, et al. Anaphylactic reactions after discontinuation of hymenoptera venom immunotherapy: A clonal mast cell disorder should be suspected. J Allergy Clin Immunol Pract 2018;6(4):1368-72.

5I. Alvarez-Twose I, Gonzalez-de-Olano D, Sanchez-Munoz L, Matito A, Jara-Acevedo M, Teodosio C, et al. Validation of the REMA score for predicting mast cell clonality and systemic mastocytosis in patients with systemic mast cell activation symptoms. Int Arch Allergy Immunol 2012;157(3):275-80.

52. Valent P, Sotlar K, Sperr WR, Escribano L, Yavuz S, Reiter A, et al. Refined diagnostic criteria and classification of mast cell leukemia (MCL) and myelomastocytic leukemia (MML): a consensus proposal. Ann Oncol 2014;25(9):1691-700.

53. Rama T, MorgadoJM, Escribano L, Alvarez-Twose I, Sanchez-Muñoz L, Moreira A, et al. Mastocytosis: NSAIDs are safer than previously thought. Clin Transl Allergy 20I8;8(S3):PI27.

54. Dewachter P, Castells MC, Hepner DL, Mouton-Faivre C. Perioperative management of patients with mastocytosis. Anesthesiology 2014;120(3):753-9.

55. Matito A, Morgado JM, Sanchez-Lopez P, Alvarez-Twose I, Sanchez-Munoz L, Orfao A, et al. Management of anesthesia in adult and pediatric mastocytosis: A study of the spanish network on mastocytosis (REMA) based on 726 anesthetic procedures. Int Arch Allergy Immunol 2015;167(I):47-56.

56. Zanoni G, Zanotti R, Schena D, Sabbadini C, Opri R, Bonadonna $P$. Vaccination management in children and adults with mastocytosis. Clin Exp Allergy 2017;47(4):593-6.

57. Soter NA, Austen KF, Wasserman SI. Oral disodium cromoglycate in the treatment of systemic mastocytosis. N Engl J Med 1979; 30I(9):465-9.
58. Horan RF, Sheffer AL, Austen KF. Cromolyn sodium in the management of systemic mastocytosis. J Allergy Clin Immunol 1990; 85(5):852-5.

59. Escribano L, Akin C, Castells M, Schwartz LB. Current options in the treatment of mast cell mediator-related symptoms in mastocytosis. Inflamm Allergy Drug Targets 2006;5(I):6I-77.

60. Czarnetzki BM, Behrendt H. Urticaria pigmentosa: clinical picture and response to oral disodium cromoglycate. $\mathrm{Br} J$ Dermatol 1981;105(5):563-7.

61. Frieri M, Alling DW, Metcalfe DD. Comparison of the therapeutic efficacy of cromolyn sodium with that of combined chlorpheniramine and cimetidine in systemic mastocytosis. Results of a double-blind clinical trial. Am J Med 1985;78(I):9-14.

62. Liberman D, Herskovitz T, Alroy G. Oral disodium cromoglycate in the treatment of systemic mastocytosis. Harefuah 1980;99(I2): 43I-2.

63. Metcalfe DD. The treatment of mastocytosis: an overview. J Invest Dermatol. 1991;96(3):55S-6S; discussion 6S-9S.

64. Welch EA, Alper JC, Bogaars H, Farrell DS. Treatment of bullous mastocytosis with disodium cromoglycate. J Am Acad Dermatol 1983;9(3):349-53.

65. Siebenhaar F, Akin C, Bindslev-Jensen C, Maurer M, Broesby-Olsen S. Treatment strategies in mastocytosis. Immunol Allergy Clin North Am 20I4;34(2):433-47.

66. Alexander RR. Disodium cromoglycate in the treatment of systemic mastocytosis involving only bone. Acta Haematol. 1985;74(2):108-10.

67. Brazzelli V, Grassi S, Merante S, Grasso V, Ciccocioppo R, Bossi $G$, et al. Narrow-band UVB phototherapy and psoralen-ultraviolet A photochemotherapy in the treatment of cutaneous mastocytosis: a study in 20 patients. Photodermatol Photoimmunol Photomed 2016;32(5-6):238-46.

68. Valent P, Akin C, Hartmann K, Nilsson G, Reiter A, Hermine O, et al. Advances in the Classification and Treatment of Mastocytosis: Current Status and Outlook toward the Future. Cancer Res 2017;77(6):126I-70.

69. Pardanani A. How I treat patients with indolent and smoldering mastocytosis (rare conditions but difficult to manage). Blood 2013;12I(16):3085-94.

70. Arock M, Akin C, Hermine O, Valent P. Current treatment options in patients with mastocytosis: status in 2015 and future perspectives. Eur J Haematol 2015;94(6):474-90.

7I. Valent P, Sperr WR, Akin C. How I treat patients with advanced systemic mastocytosis. Blood 2010;116(26):5812-7.

72. Alvarez-Twose I, Matito A, Morgado JM, Sanchez-Munoz L, Jara-Acevedo M, Garcia-Montero A, et al. Imatinib in systemic mastocytosis: a phase IV clinical trial in patients lacking exon 17 KIT mutations and review of the literature. Oncotarget 2016. 
73. Kasamon YL, Ko CW, Subramaniam S, Ma L, Yang Y, Nie L, et al. FDA Approval Summary: Midostaurin for the treatment of advanced systemic mastocytosis. The Oncologist 2018;23(I2): I5II-9.

74. Gotlib J, Kluin-Nelemans HC, George TI, Akin C, Sotlar K, Hermine $\mathrm{O}$, et al. Efficacy and safety of midostaurin in advanced systemic mastocytosis. N Engl J Med 2016;374(26):2530-4I.

75. DeAngelo DJ, George TI, Linder A, Langford C, Perkins C, Ma J, et al. Efficacy and safety of midostaurin in patients with advanced systemic mastocytosis: 10-year median follow-up of a phase II trial. Leukemia 2018;32(2):470-8.

76. van Anrooij B, Oude Elberink JNG, Span LFR, de Monchy JGR, Rosati S, Mulder AB, et al. Midostaurin in patients with indolent systemic mastocytosis: An open-label phase 2 trial. J Allergy Clin Immunol 20I8;142(3):1006-8 e7.
77. Lei D, Akin C, Kovalszki A. Management of mastocytosis in pregnancy: A review. J Allergy Clin Immunol Pract 2017.

78. Matito A, Alvarez-Twose I, MorgadoJM, Sanchez-Munoz L, Orfao A, Escribano L. Clinical impact of pregnancy in mastocytosis: a study of the spanish network on mastocytosis (REMA) in 45 cases. Int Arch Allergy Immunol 20II;156(I):104-II.

79. Kallen B. Use of antihistamine drugs in early pregnancy and delivery outcome. J Matern Fetal Neonatal Med 2002; II(3):I46-52.

80. Garbis H, Elefant E, Diav-Citrin O, Mastroiacovo P, Schaefer C, Vial T, et al. Pregnancy outcome after exposure to ranitidine and other H2-blockers. A collaborative study of the European Network of Teratology Information Services. Reprod Toxicol 2005;19(4):453-8. 